\title{
Increased growth rate of anodic porous alumina by use of ionic liquid as electrolyte additive
}

\author{
Marco Salerno *, Niranjan Patra, Romeo Losso, Roberto Cingolani \\ Italian Institute of Technology, via Morego 30, Genova, I-16163, Italy
}

\section{A R T I C L E I N F O}

Article history:

Received 6 May 2009

Accepted 20 May 2009

Available online 3 June 2009

\section{Keywords:}

Nanomaterials

Porosity

Alumina

Anodization

Ionic liquid

Growth rate

\begin{abstract}
A B S T R A C T
The use of ionic liquids 1-Butyl-3-methylimidazolium 2-(2-methoxyethoxy) ethyl sulfate and 1-Butyl-3methylimidazolium tetrafluoborate has been tested in the fabrication of anodic porous alumina. The anodizations of the aluminium substrate have been carried out in oxalic acid in galvanostatic mode. During anodization with 1-Butyl-3-methylimidazolium tetrafluoborate added electrolyte, proper tuning of the current density and of the additive concentration resulted in a three-fold increase of the growth rate as compared to the bare acidic solution with the same acid concentration. This did not cause cracks in the film during growth, and did not affect the regular structure of the pores at the interface with the substrate.
\end{abstract}

(c) 2009 Elsevier B.V. All rights reserved.

\section{Introduction}

Anodic porous alumina (APA [1-4]) is a material of technological interest in a number of fields, from photonic crystals $[5,6]$ to biosensors [7], on to template-based fabrication of metal nanowires [8-10] and oxide or polymer nanotubes [11,12]. However, for several applications an APA thickness $h$ higher than $100 \mu \mathrm{m}$ is required, for the material to be robust enough to work as a standalone film, or to exhibit pore aspect ratio higher than 1000 [6,13]. Unfortunately, the film growth rate $v_{\mathrm{g}}$ reported so far for conventional mild anodization (MA) has been generally well below $1 \mu \mathrm{m} / \mathrm{min}$ [14]. This slow growth discourages the use of APA both in fundamental investigations by the research community and in the development of industrial fabrication. A viable way to speed up APA fabrication has been reported, based on a combination of MA with hard anodization (HA) [14], and values above the $1 \mu \mathrm{m} / \mathrm{min}$ threshold have also been obtained in MA only, by proper optimization of all the process parameters, after a detailed analysis of the involved model $[15,16]$. Another possible route could be the identification of additives that can conveniently change the environmental conditions for anodization. In this work we have tested two ionic liquids (IL) $[17,18]$ which have been added to oxalic acid as the working electrolyte (EL). The idea behind using IL additives is that by proper selection of the molecule and of its concentration a catalytic effect can perhaps be obtained on the anodization reactions.

\footnotetext{
* Corresponding author. Tel.: +39 1071781 444; fax: +39 10720321. E-mail address: marco.salerno@iit.it (M. Salerno).
}

\section{Experimental}

\subsection{Sample fabrication}

We used $0.25 \mathrm{~mm}$ thick foils of polycrystalline Al (Goodfellows, 99.999\% purity), which were treated on both dipped faces during both electropolishing and anodization. Degreasing was done with acetone first and ethanol afterwards, finally rinsing in running DI water.

Electropolishing was performed on the $\mathrm{Al}$ in a $1: 5 \mathrm{v} / \mathrm{v} \mathrm{HClO}{ }_{4}: \mathrm{C}_{2} \mathrm{H}_{5} \mathrm{OH}$ mixture, inside a refrigerating bath set at $T_{\text {bath }}=+7^{\circ} \mathrm{C}$. The process was run for 7 min without stirring, at constant current density $J_{\mathrm{EP}} \sim 170 \mathrm{~mA} /$ $\mathrm{cm}^{2}$. The final $\mathrm{Al}$ surface looked mirror-like, and the local root mean square roughness measured by atomic force microscopy (AFM) had decreased from $\sim 150$ to $\sim 5 \mathrm{~nm}$, for $30 \mu \mathrm{m}$ scan size.

As the EL we chose an aqueous solution of oxalic acid $\left((\mathrm{COOH})_{2}\right.$, Sigma-Aldrich, Italy). Anodization was also run at $T_{\text {bath }}=+7{ }^{\circ} \mathrm{C}$ without stirring as for electropolishing. We have only run single anodization processes, and considered the inner APA surface (in contact with the Al substrate) as the test surface for the quality of pore arrangement. The anodizations were all run for a total anodization time $t_{\text {end }}=30 \mathrm{~min}$, with current density J ranging from 20 to $600 \mathrm{~mA}$ / $\mathrm{cm}^{2}$.

As ILs to test we selected two different commercially available room temperature water-soluble ILs, namely 1-Butyl-3-methylimidazolium 2-(2-methoxyethoxy) ethyl sulfate $\left(\mathrm{C}_{13} \mathrm{H}_{26} \mathrm{~N}_{2} \mathrm{O}_{6} \mathrm{~S}\right.$, "IL1") and 1-Butyl3-methylimidazolium tetrafluoborate $\left(\mathrm{C}_{8} \mathrm{H}_{15} \mathrm{BF}_{4} \mathrm{~N}_{2}\right.$, "IL2"), both from Sigma-Aldrich. The reason for this choice was that both the mentioned ionic liquids were expected to be well soluble in water, particularly the former being quite rich in oxygen content. 


\subsection{Sample characterization}

For removal of the Al substrate, which was necessary to access the inner APA surface and determine the APA thickness $h$, we run a second electropolishing-like process step, at room temperature and current density $\sim 10 J_{\mathrm{EP}}$. The reason for this choice instead of the common chemical etching was to force Al dissolution between the two closely spaced APA surfaces opposing to each other, which would prevent acid diffusion otherwise. The process was stopped when a significant loss of Al had been observed at the anode, enough for optical and AFM inspection (typically after $t \sim 30 \mathrm{~s}$ ).

The APA outer and inner surfaces were imaged by means of a MFP3D AFM (Asylum Research, USA), operating in Tapping mode. The APA $h$ was then measured by optical micrographs acquired in reflection perpendicular to the film sections, with $a \pm 1 \mu \mathrm{m}$ resolution uncertainty.

\section{Results and discussion}

Al anodization relies on the balance between the chemical dissolution rate of the alumina and the diffusion rate of the involved ions, namely the incoming $\mathrm{O}^{2-}$ and the outcoming $\mathrm{Al}^{3+}$, with respect to the anode. Therefore if the growth rate $v_{\mathrm{g}}$ is the parameter of main interest, which is correlated with the ion transport rate and so the anodization current, galvanostatic anodization has to be preferred against potentiostatic one [19-21]. In the following we assume a simplified model in which the current efficiency is not affected either by changing the current in the considered range or by addition of the IL molecules, and correlates linearly with the anionic current through the barrier layer. In Fig. 1 a few voltage-time characteristic curves $V(t)$ acquired during galvanostatic anodization in our setup are displayed. For the green curve the oxalic acid concentration was $0.3 \mathrm{M}$, as commonly adopted with this EL [2,14,21-29], and it was $J=100 \mathrm{~mA}$ / $\mathrm{cm}^{2}$. The same $J$ set for a diluted $0.03 \mathrm{M}$ solution required an approximately double $V(t)$ (black curve), probably due to the thicker barrier layer and to processes occurring inside it.

A linear relationship between $J$ and $h$ is expected $[3,30]$, such that to obtain higher $h$ (and thus $v_{\mathrm{g}}$ ) generally a higher $J$ should be set. However, the red curve shows that when in the $0.3 \mathrm{M}$ oxalic acid $J$ was doubled to $200 \mathrm{~mA} / \mathrm{cm}^{2}$, after reaching a critical value $V_{\text {crit }} \sim 95 \mathrm{~V}$ in

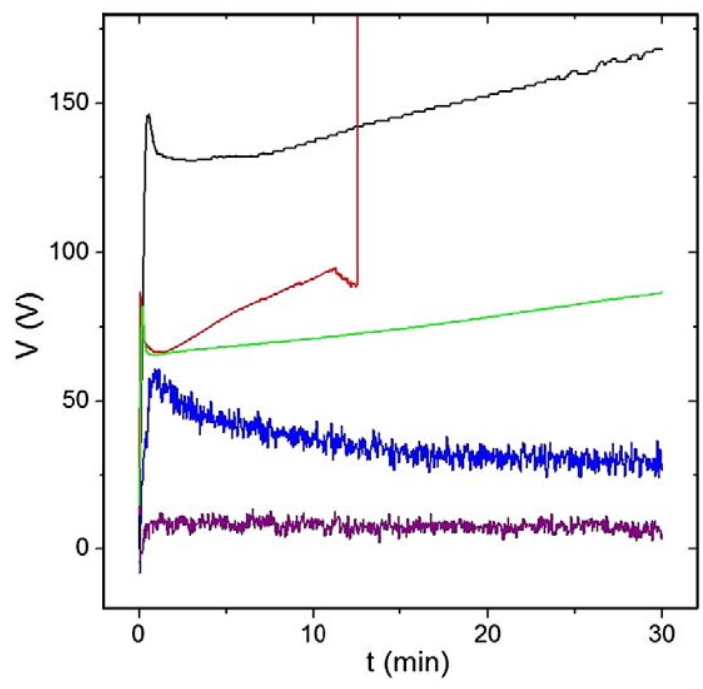

Fig. 1. Anodization voltage curves. $V(t)$ characteristic curves obtained for galvanostatic anodization. In all cases it was $J=100 \mathrm{~mA} / \mathrm{cm}^{2}$ but for the red line $\left(J=200 \mathrm{~mA} / \mathrm{cm}^{2}\right)$. Anodization conditions, from top to bottom: black line: $0.03 \mathrm{M}$ oxalic acid; red line: $0.3 \mathrm{M}$ oxalic acid, $J=200 \mathrm{~mA} / \mathrm{cm}^{2}$; green line: $0.3 \mathrm{M}$ oxalic acid; blue line: $0.5 \% \mathrm{v} / \mathrm{v}$ IL2 in $0.03 \mathrm{M}$ oxalic acid; purple line: $0.5 \% \mathrm{v} / \mathrm{v}$ IL1 in $0.03 \mathrm{M}$ oxalic acid. (For interpretation of the references to colour in this figure legend, the reader is referred to the web version of this article.) (a)

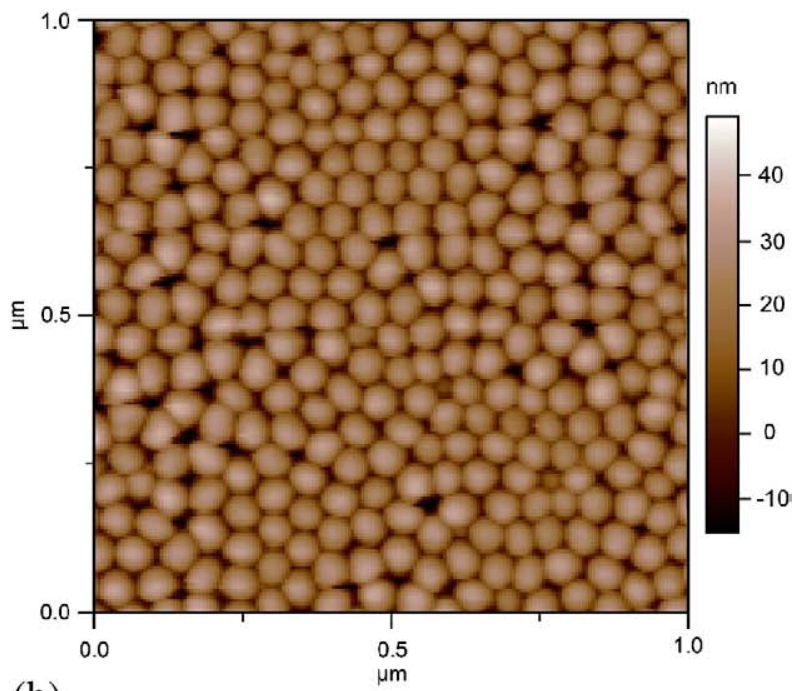

(b)

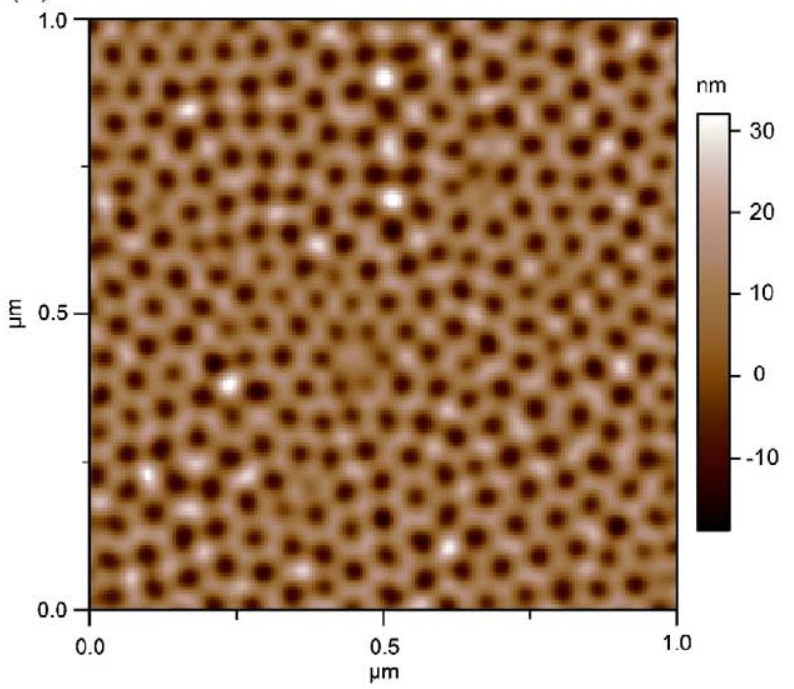

Fig. 2. AFM images of the Inner APA surface. AFM topography images of the typical inner APA surface obtained by anodization in $0.5 \% \mathrm{v} / \mathrm{v}$ IL2, a) before, and b) after chemical barrier layer removal (pore opening) by immersion for $1 \mathrm{~h}$ in $5 \%$ wt $\mathrm{H}_{3} \mathrm{PO}_{4}$ at $35{ }^{\circ} \mathrm{C}$, (image has been low pass filtered for removal of grainy defects).

$t_{\text {crit }} \sim 12 \min , V(t)$ started to decrease with some fluctuations, and finally increased up to the maximum power supply voltage. An $\mathrm{Al}$ etching side reaction had developed at the air-EL meniscus, which ended up with an open electrical circuit. The APA thickness measured for the piece of anode fallen in the EL was $h_{\text {crit }}=11 \mu \mathrm{m}$. From this value and from the above maximum voltage $V_{\text {crit }}$ reached until the voltage was increasing without perturbations in its trend, an estimate of a critical value of electric field can be obtained as $E_{\text {crit,etching }}=V_{\text {crit }} /$ $h_{\text {crit }} \sim 8.6 \mathrm{MV} / \mathrm{m}$. This is $\sim 43 \%$ lower than the dielectric strength of compact alumina, $E_{\text {break,compact }} \sim 15 \mathrm{MV} / \mathrm{m}$ [31]. In fact, when using the ten-fold diluted oxalic acid we could reach a $V_{\text {crit }} \sim 175 \mathrm{~V}$ before that breakdown occurred (curve not shown), accompanied by a decrease of $V(t)$ to zero. The respective $h_{\text {crit }} \sim 13 \mu \mathrm{m}$ gave $E_{\text {break,porous }}=V_{\text {crit }}{ }^{\prime} /$ $h_{\text {crit }}{ }^{\prime} \sim 13.5 \mathrm{MV} / \mathrm{m}$, closer to $E_{\text {break,compact }}$ but still lower than that value. The sequence of values $E_{\text {crit,etching }}<E_{\text {break,porous }}<E_{\text {break,compact }}$ is as expected, since the breakdown field of compact alumina is an upper limit that cannot be reached by porous alumina, where only a small portion of its thickness $h$ is associated with a compact barrier layer. In turn, in the first case described above the electric field did not reach the maximum value corresponding to porous alumina breakdown, 
due to the side effect reactions of Al etching. This etching did not occur in the ten-fold diluted acid, which had much lower dissolving power.

If the side effect of anode cutting is not considered, the anodization in bare concentrated $(0.3 \mathrm{M})$ oxalic acid provided the highest $h$ value for $J=200 \mathrm{~mA} / \mathrm{cm}^{2}$, red line in Fig. 1, corresponding to a maximum (non-linear) mean growth rate $v_{\mathrm{g}}^{\max }=h_{\text {crit }} / t_{\text {crit }} \sim 0.83 \mu \mathrm{m} / \mathrm{min}$.

The blue and the violet curves in Fig. 1 show the $V(t)$ for $0.03 \mathrm{M}$ oxalic acid to which the same amount of IL2 and IL1 has been added, respectively. The quantity of added IL was expressed as the volume concentration $c$ relative to the oxalic acid solution, $(\mathrm{v} / \mathrm{v}, \%)$. In both the above cases it was $c=0.5 \%$. Obviously, both anodizing systems including IL1 and IL2 additive showed an overall conductivity higher than the system operated with bare oxalic acid. It is clear from Fig. 1 that by keeping $V$ low via the IL additive one can run anodization at comparatively high $J$, as compared to standard values reported in the literature for bare oxalic acid, and still operate in MA (i.e. low V) condition. Furthermore, the curve trend (after the initial transients) became that of a horizontal line. This is the same effect that can be obtained by operating the anodization at higher temperature, e.g. at room temperature. In case of two-step anodization these conditions would help to keep $\mathrm{V}$ as close as possible to the value required for optimally ordered APA growth, (40-60 V range or oxalic acid $[3,4])$. In our case these conditions have always allowed to avoid barrier breakdown, and to preserve the regular pore array structure on the inner APA surface (see Fig. 2).

From Fig. 1 we observe that the anodizations run at the same current density $\left(J=100 \mathrm{~mA} / \mathrm{cm}^{2}\right)$ in the bare oxalic acid solutions resulted in approximately the same final APA thickness $(h \sim 20 \mu \mathrm{m})$, as expected in galvanostatic mode under the assumption of similar current efficiency, despite the factor ten difference in concentration (black curve: $0.03 \mathrm{M}$, green curve: $0.3 \mathrm{M}$ oxalic acid). On the contrary, for the solutions added with the different ionic liquids, the same current density gave different results in formation of APA. Fig. 1 shows that the resulting conductivity of the anodizing system with IL1-added EL was four times as much as that of the anodizing system with the IL2-added EL. However, APA films were observed after anodizations with IL1 only for the lowest relative concentrations explored, $c=0.01 \%$, and with low $J=20 \mathrm{~mA} / \mathrm{cm}^{2}$. In those conditions $h$ was quite low $\left(h_{\mathrm{IL} 1}=5-10 \mu \mathrm{m}\right)$, as expected due to the low $J$, while for higher $J$ and/or $c$ black pits were observed on the Al instead of APA. Obviously the result of the high oxygen content made the dominating

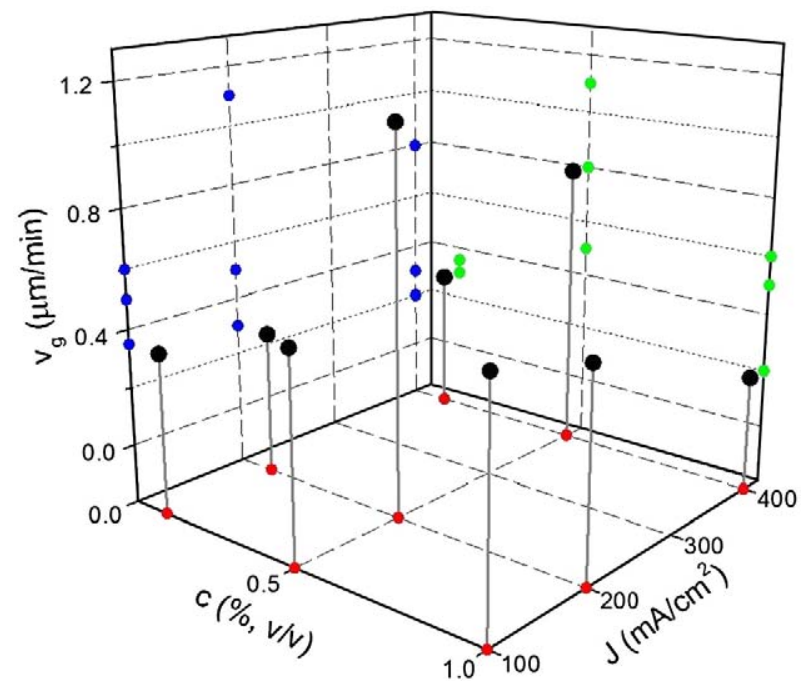

Fig. 3. Maximum of the growth rate found with use of IL2. Values of APA growth rate $v_{\mathrm{g}}$ measured for $t_{\mathrm{end}}=30 \mathrm{~min}$, for different combinations of IL2 relative concentration $c$ and current density $J$. (Small colored circles: projections of the data points to the axis planes). (For interpretation of the references to colour in this figure legend, the reader is referred to the web version of this article.) effect of IL1 at high anodization current density to be a substrate damage after the high rate of impinging ions.

For IL2 we have systematically investigated the results of anodizations run for different combinations of $c$ and $J$, in the range $c=0.01-2 \%$ and $J=20-600 \mathrm{~mA} / \mathrm{cm}^{2}$. In particular, in Fig. 3b) the $(c, J)$ phase space combinations of the values $c=0.1,0.5$ and $1.0 \%$ and $J=100,200$ and $400 \mathrm{~mA} / \mathrm{cm}^{2}$ are shown, with respect to the resulting APA growth rate. A local maximum of $v_{\mathrm{g}}$ appears for $(c, J)=\left(0.5 \%, 200 \mathrm{~mA} / \mathrm{cm}^{2}\right)$, with value $v_{\mathrm{g}}^{\max }($ IL2) $=1.1 \mu \mathrm{m} / \mathrm{min}$. This growth rate is higher, without catastrophic side effects such as Al etching, than the maximum value obtained for the same acidic EL with ten-fold higher concentration (corresponding to the red curve in Fig. $\left.1, v_{\mathrm{g}, \max }(0.3 \mathrm{M})=h_{\text {crit }} / t_{\text {crit }} \sim 0.9 \mu \mathrm{m} / \mathrm{min}\right)$, and more than three times higher than for the EL solution with the same acid concentration and current density $\left(J=200 \mathrm{~mA} / \mathrm{cm}^{2}\right)$ but without IL, (corresponding to the black curve in Fig. $1, v_{\mathrm{g}}(0.03 \mathrm{M})=h_{\mathrm{end}} / t_{\text {end }} \sim 10 \mu \mathrm{m} /$ $30 \mathrm{~min} \sim 0.3 \mu \mathrm{m} / \mathrm{min}, h$ measurement not shown).

For too high $J$ values, side effects can negatively affect APA formation, as outlined previously, with a consequent loss of current efficiency. On the other hand, too many ions from IL1 in solution can decrease the current efficiency in turn, as the current will be consumed to other reactions involving e.g. deformation of IL ions. The molar ratio of the IL-oxalic acid species in the experimentally observed best condition of $0.5 \% \mathrm{v} / \mathrm{v}$ for IL2 can be calculated. The numbers of moles for each species are $n_{\mathrm{ox}}=\mathrm{M}_{\mathrm{ox}} \mathrm{V}_{\mathrm{ox}}$, where $\mathrm{M}_{\mathrm{ox}}$ is the molarity and $\mathrm{V}_{\mathrm{ox}}$ the volume of oxalic acid, and $n_{\mathrm{IL} 2}=m_{\mathrm{IL} 2} / \mathrm{MM}_{\mathrm{IL} 2}$, where $m_{\mathrm{IL} 2}$ is the mass and $\mathrm{MM}_{\mathrm{IL} 2}$ the molar mass of IL2, respectively. Therefore, the molar ratio is $n_{\mathrm{ox}} / n_{\mathrm{IL} 2}=\mathrm{M}_{\mathrm{ox}} \mathrm{MM}_{\mathrm{IL} 2} / \rho_{\mathrm{IL} 2} c$, with $\rho_{\mathrm{IL} 2}$ the mass density of IL2. Since it is $\mathrm{MM}_{\mathrm{IL} 2}=226.03 \mathrm{~g} / \mathrm{mole}$ and $\rho_{\mathrm{IL} 2}=1.21 \mathrm{~g} / \mathrm{mL}$, for $c=0.5 \%$ it turns out $n_{\text {oxalic }} / n_{\mathrm{IL} 2} \sim 1.1$. Obviously the best improvement in $v_{\mathrm{g}}$ on addition of IL2 was obtained for a $\sim 1: 1$ ratio of the IL2 moles with respect to the oxalic acid moles. When this ratio was increased of a factor two it was not possible to grow APA any more even with IL2. On the contrary, anodization run with the same ratio obtained for example by doubling both concentrations $\left(\mathrm{M}_{\mathrm{ox}}=0.06 \mathrm{M}\right.$ and $\left.c_{\mathrm{IL} 2}=1 \%\right)$ gave APA with consistent $h$ values.

\section{Conclusions}

We have investigated the effect of addition of 1-Butyl-3-methylimidazolium 2-(2-methoxyethoxy) ethyl sulfate and 1-Butyl-3-methylimidazolium tetrafluoborate into oxalic acid solutions commonly used for APA fabrication. These two ILs have been used for the first time as additives in this task. In particular, by adding 1-Butyl-3methylimidazolium tetrafluoborate in an 1:1 molar ratio with the acid and properly tuning the current, we could obtain an APA growth rate of $1.1 \mu \mathrm{m} / \mathrm{min}$. This is comparable to the values of industrial HA processes, but has been obtained in MA conditions. Therefore our process should make it possible to obtain thick APA layers in comparatively short times (few hours) and with ordered pore arrays also on the outer surface, after two-step anodization in the appropriate $\mathrm{V}$ range. Similarly high growth rates have also been obtained recently without additives $[15,16]$ on proper optimization of the operating conditions, after working out a full model of the anodization procedure. However, our increase in growth rate is interesting per se and worth being further investigated for possible applications after further optimization and for a better understanding of the mechanism underlying the observed effect.

\section{References}

[1] Diggle JW, Downie TC, Goulding CW. Anodic oxide films on aluminum. Chem Rev 1969;69:365-405.

[2] Masuda H, Fukuda K. Ordered metal nanohole arrays made by a two-step replication of honeycomb structures of anodic alumina. Science 1995;268:1466-8.

[3] Thompson GE. Porous anodic alumina: fabrication, characterization and applications. Thin Solid Films 1997;297:192-201.

[4] Li F, Zhang L, Metzger RM. On the growth of highly ordered pores in anodized aluminum oxide. Chem Mater 1998;10:2470-80. 
[5] Li A-P, Müller F, Birner A, Nielsch K, Gösele U. Fabrication and microstructuring of hexagonally ordered two-dimensional nanopore arrays in anodic alumina. Adv Mater 1999;11:483-7.

[6] Sauer G, Brehm G, Schneider S, Nielsch K, Wehrspohn RB, Choi J, et al. Highly ordered monocrystalline silver nanowire arrays. J Appl Phys 2002;91:3243-7.

[7] Stura E, Bruzzese D, Valerio F, Grasso V, Perlo P, Nicolini C. Anodic porous alumina as mechanical stability enhancer for LDL-cholesterol sensitive electrodes. Biosens Bioel 2007;23:655-60.

[8] Bao X, Li F, Metzger RM. Synthesis and magnetic properties of electrodeposited metal particles on anodic alumite film. J Appl Phys 1996;79:4866-8.

[9] Li F, Metzger RM. Activation volume of alpha-Fe particles in alumite films. J Appl Phys 1997;81:3806-8.

[10] Sun M, Zangari G, Metzger RM. Cobalt island arrays with in-plane anisotropy electrodeposited in highly ordered alumite. IEEE Trans Magn 2000;36:3005-8.

[11] Hong JF, Lee W, Scholz R, Dadgar A, Krost A, Nielsch K, et al. Arrays of vertically aligned and hexagonally arranged $\mathrm{ZnO}$ nanowires: a new template-directed approach. Nanotechnology 2005;16:913-7.

[12] Grimm S, Giesa R, Sklarek K, Langner A, Gösele U, Schmidt H-W, et al. Nondestructive replication of self-ordered nanoporous alumina membranes via cross-linked polyacrylate nanofiber arrays. Nano Letters 2008;8:1954-9.

[13] Wehrspohn RB, Birner A, Müller F, Nielsch K, Schilling J, Gösele U. Electrochemically-prepared highly-ordered high-aspect-ratio pore arrays. In: Schmuki P, Lockwood DJ, Ogata YH, Isaacs HS, editors. Pits and Pores: PV-2000-25, Electrochemical Society Proceedings. Pennington; 2000. p. 168.

[14] Lee W, Ji R, Gösele U, Nielsch K. Fast fabrication of long-range ordered porous alumina membranes by hard anodization. Nat Mater 2006;5:741-7.

[15] Patermarakis G, Moussoutzanis K. Development and application of a holistic model for the steady state growth of porous anodic alumina films. Electrochim Acta 2009;54:2434-43.

[16] Patermarakis G, Karayianni H, Masavetas K, Chandrinos J. Oxide density distribution across the barrier layer during the steady state growth of porous anodic alumina films: chronopotentiometry, kinetics and mass and thicknes evolution and a high field ionic migration model. J Solid State Electrochem 2009, doi:10.1007/s10008-008-0745-6.
[17] Wasserscheid P, Welton T. Ionic Liquids in Synthesis. Wiley-VCH Verlag GmbH \& Co. KGaA; 2002.

[18] Weyershausen B, Lehmann K. Industrial application of ionic liquids as performance additives. Green Chem 2005;7:15-9.

[19] Zahariev A, Kanazirski I, Girginov A. Anodic alumina films formed in sulfamic acid solution. Inorg Chim Acta 2008;361:1789-92.

[20] Lee W, Scholz R, Gösele U. A continuous process for structurally well-defined $\mathrm{Al}_{2} \mathrm{O}_{3}$ nanotubes based on pulse anodization of aluminum. Nano Letters $2008: 8: 2155-60$.

[21] Liao CL, Chu CW, Fung KZ, Leu IC. Fabrication of nanoporous metal electrode by two-step replication technique. J Alloys Comp 2007;441:L1-6.

[22] Zhou J-H, He J-P, Zhao GW, Zhang C-X, Zhao J-S, Hu H-P. Alumina nanostructures by two-step anodization process. Trans Nonferr Met Soc China 2007;17:82-6.

[23] Xu T, Zangari G, Metzger RM. Periodic holes with $10 \mathrm{~nm}$ diameter produced by grazing $\mathrm{Ar}^{+}$milling of the barrier layer in hexagonally ordered nanoporous alumina. Nano Lett 2002;2:37-41.

[24] Masuda H, Yamada H, Satoh M, Asoh H, Nakao M, Tamamura T. Highly ordered nanochannel-array architecture in anodic alumina. Appl Phys Lett 2007;71:2770.

[25] Li AP, Müller F, Birner A, Nielsch K, Gösele U. Hexagonal pore arrays with a 50 $420 \mathrm{~nm}$ interpore distance formed by self-organization in anodic alumina. J Appl Phys 1998;84:6023-6.

[26] Rahimi MH, Tabaian SH, Hoveyda, Amiri M, Dalaly MM, Saramad S, et al. The effect of aluminum electropolishing on nano-pores arrangement in anodic alumina membranes. Int J Mod Phys B 2008;22:3267-77.

[27] Zhang L, Cho HS, Li F, Metzger RM, Doyle WD. Cellular growth of highly ordered porous anodic films on aluminium. J Mater Sci Lett 1998;17:291-4.

[28] Lee W, Schwirn K, Steinhart M, Pippel E, Scholz R, Gösele U. Structural engineering of nanoporous anodic aluminium oxide by pulse anodization of aluminium. Nat Nano 2008;3:234-9.

[29] Nielsch K, Müller F, Li AP, Gösele U. Uniform nickel deposition into ordered alumina pores by pulsed electrodeposition. Adv Mat 2000;12:582-6.

[30] Bocchetta P, Sunseri C, Chavarotti G, Di Quarto F. Microporous alumina membranes electrochemically grown. Electrochim Acta 2003;48:3175-83.

[31] Martienssen W, Warlimont H, editors. Springer Handbook of Condensed Matter and Materials Data. Springer; 2005. 